\title{
Human eggs supply 'ethical' stem cells
}

Human embryonic stem-cell lines have been successfully produced without using fertilized eggs. The researchers responsible work in Italy, which has some of the most restrictive embryo-research laws in the world. They hope the work will be welcomed as an ethically acceptable source of stem cells, as it does not involve destroying a viable embrya.

Embryonic stem cells are of great interest to medical researchers because they can transform into many different cell types, such as muscle, skin or brain cells. But there are ethical worries about pursuing such research, because creating an embryonic stem-cell line involves destroying a human embryo. Many countries have either banned the process in humans, or placed restrictions on the work that can be done.

One solution is to extract stem cells from parthenotes, embryo-like structures that develop from eggs without the need for fertilization. Some animals, such as insects and sea urchins, can reproduce in this way. Mammal ian parthenotes, by contrast, always die before implanting in the womb, but they survive long enough to be a potential source of stem cells. Cell lines have been derived in the past from mice and monkeys. Now Tiziana Brevini and Fulvio Gandolfi of the University of Milan have achieved the feat in humans. From 104 eggs, donated by women at a local fertility clinic, they were able to derive two cell lines.

Because a parthenote does not have the genetic ability to form an individual, Brevini and Gandolfi have spent the past two years characterizing the cells to make certain that they behave like normal embryonic stem-cell

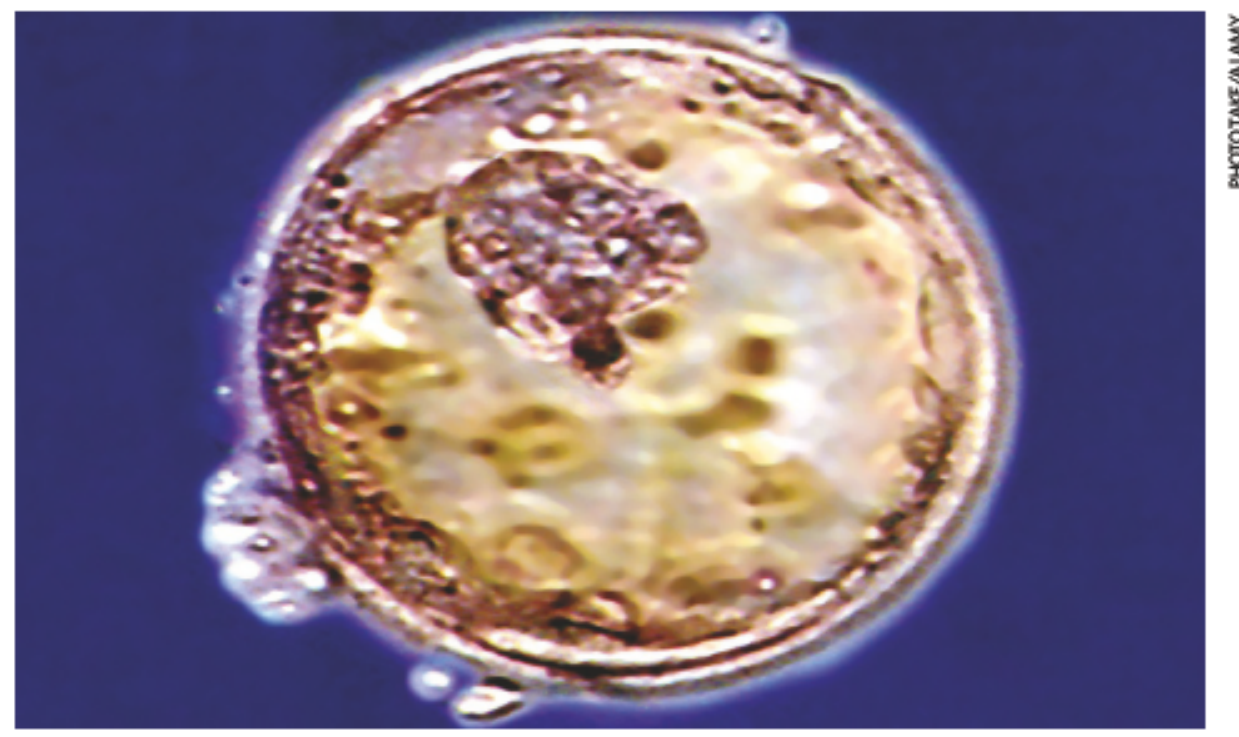

Source material destroying this early embryo to create a stem-cell line raises serious moral issues.

lines. "We wanted to be sure before saying something," notes Gandolfi. The researchers announced their results at the annual meeting of the European Society of Human Reproduction and Embryology in Prague on 21 June, alongside other teams also trying to develop alternative sources of embryonic stem cells (see 'Philosophical approach').

The work is attracting high praise from other researchers in the field. ${ }^{\circ}$ This is exciting. It was very important to show this in humans,", says Alan Trounson, a stem-cell researcher from Monash University in Melbourne, Australia. He notes that the cells seem slightly more difficult to handle than normal embry-

\section{PHILOSOPHICAL APPROACH}

Some scientists are attempting to create embryonic stem-cell lines by removing single cells from mouse embryos at the eightcell stage. The embryo remains viable after the cell has been removed, but the procedure still raises ethical questions because the singlecellitself mighthave been able to produce a whole organism.

Takumi Takeuchi of Cornell University, New York, is one of those working on this approach in mice. After seeing a presentation of his results last year, a philosopher called Matthew Liao, based at Johns Hopkins University in Baltimore, Maryland, contacted him with what he thoughtmight be a betteridea. Liao suggested letting the embryodevelop further, untilit consists of around 100 cells, and then taking four or five of those. Cells removed at this stage would still be able to form many different types of tissue, but would not be able to form a new individual. At the Prague meeting, Takeuchi revealed that he and colleagues have now derived stem-cell lines with reasonably high efficiency from 100-cell mouse embryos. The downside is that the procedure is quite invasive, and the survival rate of the embryos is cut in half. Researchers hope to improve that, but the transfer to humans will always pose an ethical problem.

If either approach could be made to work, individuals conceived through in vitro fertilization could have a stemcell line banked for use in later life. "It would be insurance for the baby," says Takeuchi. J.M. onic stem cells, but adds that it is hard to tell whether this is likely to be a general characteristic of parthenogenetic lines. "If we can learn to handle them better, this could well be an acceptable alternative to embryonic stem cells, he says. Brevini and Gandolfi plan to submit their work for publication shortly.

The researchers do not think work on parthenotes will replace conventional embryonic stem-cell research. But Brevini says she hopes it will open the field to researchers in countries with strong restrictions. In Italy, for example, the creation or destruction of human embryos for research is banned, and the United States does not allow federal money to be used for such work. Parthenote lines "may be acceptable to the US administration, so they will release funds to work on these kinds of cells", she says.

Brevini adds that she prefers to work with these lines: "I feel more comfortable dealing with a parthenote than an embryo."

One secret of the group's success seems to be its relatively plentiful supply of eggs. Italy bans the creation of more than three embryos at once during in vitro fertilization, all of which must then be implanted. More than three eggs are often extracted from women undergoing the treatment, so they can donate those left over to researchers. Unfortunately, the supply is starting to dry up as women choose to freeze their extra eggs.

Jo Marchant

Read the conference blog here

http://blogs.nature.com/ESHRE 